\title{
El compromiso docente en la educación superior actual
}

Frecuentemente se habla de los efectos de la globalización en los determinantes sociales. Las grandes naciones del mundo se reúnen a fin de tomar las mejores decisiones que permitan continuar la vida en el planeta, siendo que las instituciones formadoras deben asumir conciencia del protagonismo que les compete y trasciendan en sus egresados la responsabilidad social y ética que les concierne como ciudadanos, capaces de trabajar en los diferentes niveles de complejidad al abordar la salud individual y colectiva, respetando las diferencias culturales, étnicas, sociales, entre otras, originadas por el fenómeno de la aldea global, la cual trae cambios en la salud de las poblaciones más vulnerables, traducida en la reemergencia de enfermedades y emergencia de otras que aún no se pueden controlar; con cambios en el tablero epidemiológico, ubicándose en los primeros lugares las enfermedades crónicas influenciadas por estilos de vida poco saludables que el mismo sistema lleva a adoptar, por las exigencias de rendimiento y la velocidad de los tiempos actuales, en la que el mercado laboral exige un trabajo altamente cualificado, pero al mismo tiempo muy barato, profundizándose así el carácter explotador y discriminatorio del mismo. ${ }^{1,2}$

Frente a eso, la educación superior brindada en este siglo debe normarse dentro de un marco ético que conlleve a la persona a asumir el compromiso en el CUIDADO -el que a veces se ve obsoleto- de sí mismo, para luego poder trasladarlo hacia los demás. Vieira, citada por Vargas et al. ${ }^{3}$ refiere que el fenómeno de la globalización se expresa a través de cinco dimensiones, destacándose aquí solo dos de ellas: 1) la dimensión social, afectada por la dinámica económica y traducida en hambre, exclusión e injusticia social y, 2) la dimensión ambiental, generada por el poder de quienes defienden intereses particulares, poniendo en riesgo a toda expresión de vida; ambos aspectos permiten reflexionar sobre la importancia de la formación de la persona, con capacidad de tomar decisiones, consciente de su actuar y responsabilidad en el cuidado de la vida. Cuidado que, como lo señala Boff, citado por Vargas et al., ${ }^{3}$ debe ser desarrollado como una actitud entendida ésta como un posicionamiento ético de respeto, basado en principios de solidaridad, generosidad, amor y de virtudes, que reflejen el carácter moral que encierra el cuidado.

En esta óptica, el ejercicio de cuidar es un deber de carácter universal, que trasciende culturas y tradiciones y que pone de relieve el grado de humanidad. Este ejercicio también se aplica en las aulas en la enseñanza de enfermería, que debe estar centrada en lo que es la esencia de las acciones de la profesión: El CUIDADO. ${ }^{4}$

En este siglo, el cuidado se convierte en un reto, pues el mundo se ha tornado complejo, que para entenderlo se ha disgregado en partes que dificultan el enfoque holístico con el que se debe observar al ser (persona-usuario-comunidad). En la formación del futuro profesional de enfermería se busca conservar esa integralidad, a pesar que aún impera el modelo biomédico y que las prácticas están orientadas al desarrollo de tecnologías y protocolos, los cuáles ciertamente buscan mejorar la salud de la persona; pero también distraen la atención y soslayan un aspecto importante de la esencia del cuidado: ${ }^{5}$ dejarle ser, a través de la preservación de su identidad, compartir sus penas, angustias, alegrías y expectativas, sin que se evidencie esfuerzo alguno, a fin de que se sienta seguro y confiado en la persona que está a su lado (profesional), quién entiende que cuánto más compleja es la realidad, más necesario se hace el cuidado.

Durante la formación del profesional de enfermería se debe impregnar en los estudiantes de "algo más" que solo conocimientos y procedimientos, ${ }^{6}$ lo cual está constituido por los valores y principios, tan necesarios en el presente milenio para definir comportamientos y actitudes asertivas, fluyendo de modo natural y digno en quién los practica y en quién los recibe. Sin embargo, al incorporarse las enfermeras al ámbito laboral ingresan a un sistema normatizado, que tiende a deshumanizar el cuidado, sea por el cumplimiento de 
metas o por protocolos que universalizan las intervenciones, ${ }^{7}$ asumiendo muchas veces que calidad es sinónimo de mayor producción y menor inversión.

Esta realidad obliga abordar cambios en la educación superior, siendo el proceso de aprendizaje del estudiante y las condiciones que lo hacen posible trascedentales; entendiendo que entre esas condiciones está el rol docente, cuya responsabilidad es formar ciudadanos comprometidos con el desarrollo humano de sí mismo y de sus semejantes, quienes enfrentarán retos al tomar decisiones ante un sistema y cultura institucional que quizás sean contrarios a esta visión. Por lo tanto, formar ciudadanos con compromiso es imperativo, ya que el ecosistema está conformado por todos y juntos contribuyen con la salud global; es así que, además de abrir pautas para el conocimiento, es necesario insistir en los aspectos actitudinales que reflejan el interés hacia la persona, en otras palabras, en los valores, especialmente morales, porque son aquellos que permitirán afianzar los otros valores. En este caso, los valores ciudadanos, tales como la libertad, igualdad, solidaridad y disposición al diálogo ${ }^{8}$ facilitando la convivencia con los demás en una estela de humanismo y de interculturalidad, tan imprescindible en los tiempos de hoy.

Corresponde a quienes intervienen en el arte de formar al futuro profesional de enfermería, tejer la educación con hilos de amor, comprensión y empatía; todo este proceso en un ambiente de confianza, amabilidad y seguridad, para que ese ser se desarrolle en toda su humanidad, manteniendo su identidad personal, su autenticidad y su naturaleza.

Se hace necesario entender la naturaleza de la humanidad, como al espíritu que está dentro de una materia; con dones y cualidades deseosos de rescatar, a través de un servicio basado en la convicción de sumisión y de humildad, ante la gran fuerza de la creación, reconociendo que cada ser humano apenas es un instrumento que refleja ese infinito amor.

\section{REFERENCIAS BIBLIOGRÁFICAS}

1. Feo IO. Reflexiones sobre la globalización y su impacto en la salud laboral y ambiental. Ciencia \& Salude Coletiva [serie de internet], 2003 [citado 02 de feb 2015]; 8(4): 887-96. http://www.scielo.br/scielo.php?pid=S1413-81232003000400011\&script=sci_arttext

2. Prado ML, Reibnitz KS. Salud y globalización: retos futuros para el cuidado de enfermería. Invest Educ Enferm [serie de internet]. 2004 [citado 15 de feb 2015]; 22(2): 104-11. http://aprendeenlinea.udea.edu.co/revistas/index.php/iee/article/viewFile/2964/2675

3. Vargas LA, Andrés JPT, Oliveira TFV, Las relaciones entre la globalización, Medio ambiente y Salud: Retos para la enfermería en el siglo XXI. Index Enfern [serie de internet]. Sep 2010 [citado 15 de feb 2015]; 19(2-3): [aproximadamente 07 laudas]. Disponible en: http://scielo.isciii.es/scielo.php?script=sci_arttext\&pid=S113212962010000200018

4. WaldowVR. Enseñanza de enfermería centrada en el cuidado. CHIA [serie de internet]. Dic 2009 [citado 02 de mar 2015]; 9(3): 246-56. Disponible en: http://aquichan.unisabana.edu.co/index.php/aquichan/article/view/1523/1970

5. Troncoso MP, Suazo SV. Cuidado Humanizado un desafío para las enfermera en los servicios hospitalarios. Acta Paul Enferm [serie de internet]. [citado 02 de mar 2015]; 20(4): 499-501. Disponible en: http://www.scielo.br/pdf/ape/v20n4/18.pdf

6. Ceballos VPA. Desde los ámbitos de enfermería, analizando el cuidado humanizado. Ciencia y Enfermería [serie de internet]. 2010 [citado 15 de ene 2015]; XVI (1): 31-5. Disponible en: http://www.scielo.cl/pdf/cienf/v16n1/art_04.pdf

7. Arredondo-Gonzales CP, Siles-González J. Tecnología y humanización de los cuidados. Una mirada desde la teoría de las relaciones interpersonales. Index Enferm [serie de internet]. Ene-mar 2009 [citado 13 de ene 2015]; 18(1): [aproximadamente 07 laudas]. Disponible en: http://scielo.isciii.es/scielo.php?pid=S1132$12962009000100007 \&$ script=sci_arttext

8. Cortina A. Ciudadanos del mundo, hacia una teoría de la ciudadanía [internet]. Madrid-España: Alianza Editorial; 2001 [citado 10 de dic 2014]. 36 p. Disponible en: http://www.culturadelalegalidad.org.mx/recursos/Contenidos/Estudiosacadmicosyestadsticos/documentos/Ciud adanos20del20Mundo,20Adela20Cortina.pdf 